\title{
The neural correlates of deficient error awareness in attention-deficit hyperactivity disorder (ADHD)
}

\author{
Redmond G. O’Connell a,b,*, Mark A. Bellgrove ${ }^{c}$, Paul M. Dockree ${ }^{a, b}$, Adam Lau $^{d}$, Robert Hester ${ }^{c}$, \\ Hugh Garavan $^{\mathrm{a}}$, Michael Fitzgerald ${ }^{\mathrm{d}}$, John J. Foxe ${ }^{\mathrm{b}, \mathrm{e}, \mathrm{f}}$, Ian H. Robertson ${ }^{\mathrm{a}}$ \\ a School of Psychology and Trinity College Institute of Neuroscience, Lloyd Building, Trinity College Dublin, Dublin 2, Ireland \\ b The Cognitive Neurophysiology Laboratory, St Vincents Hospital, Fairview, Dublin 3, Ireland \\ c Cognitive Neuroscience Laboratory, School of Psychology and Queensland Brain Institute, University of Queensland, Brisbane, Australia \\ d Department of Psychiatry, Trinity College Dublin, Dublin 2, Ireland \\ e The Cognitive Neurophysiology Laboratory, Nathan S. Kline Institute for Psychiatric Research, Orangeburg, New York, NY 10962, USA \\ f Program in Cognitive Neuroscience, Department of Psychology, The City College of the City University of New York, 138th St. E Convent Avenue, New York, NY 10031, USA
}

\section{A R T I C L E I N F O}

\section{Article history:}

Received 7 July 2008

Received in revised form 19 December 2008

Accepted 7 January 2009

Available online 16 January 2009

\section{Keywords:}

Error awareness

ADHD

ERP

Source analysis

Anterior cingulate cortex

\begin{abstract}
A B S T R A C T
The ability to detect and correct errors is critical to adaptive control of behaviour and represents a discrete neuropsychological function. A number of studies have highlighted that attention-deficit hyperactivity disorder (ADHD) is associated with abnormalities in behavioural and neural responsiveness to performance errors. One limitation of previous work has been a failure to determine the extent to which these differences are attributable to failures of conscious error awareness, a process that is dependent on the integrity of the frontal lobes. Recent advances in electrophysiological research make it possible to distinguish unconscious and conscious aspects of error processing. This study constitutes an extensive electrophysiological investigation of error awareness and error processing in ADHD. A Go/No-Go response inhibition task specifically designed to assess error awareness was administered to a group of adults diagnosed with ADHD and a group of matched control participants. The ADHD group made significantly more errors than the control group but was less likely to consciously detect these errors. An analysis of eventrelated potentials elicited by errors indicated that an early performance monitoring component (early positivity) was significantly attenuated in the ADHD group as was a later component that specifically reflects conscious error processing $(\mathrm{Pe})$. Dipole source modelling suggested that abnormal Pe amplitudes were attributable to decreased activation of the anterior cingulate cortex. Decreased electrodermal activity in the ADHD group also suggested a motivational insensitivity to performance errors. Our data provide evidence that neuropsychological deficits associated with ADHD can be exacerbated by error processing abnormalities. Error awareness may represent an important cognitive and physiological phenotype for ADHD.
\end{abstract}

(C) 2009 Elsevier Ltd. All rights reserved.

\section{Introduction}

In everyday life the ability to detect errors is critical for smooth and dynamic interaction with our environment, providing us with the opportunity to re-align our behaviour with prevailing goals and to learn the consequences of different behaviours (Norman \& Shallice, 1986). Recent evidence from functional imaging shows that error processing is a discrete component of executive control supported by distinct brain networks dedicated to the detection and correction of performance errors (Fiehler, Ullsperger, \& von Cramon, 2004; Garavan, Ross, Murphy, Roche, \& Stein, 2002). The ante-

\footnotetext{
* Corresponding author at: School of Psychology and Trinity College Institute of Neuroscience, Lloyd Building, Trinity College Dublin, Dublin 2, Ireland.

E-mail address: reoconne@tcd.ie (R.G. O'Connell).
}

rior cingulate cortex (ACC) and lateral prefrontal cortex have been identified as the cortical areas that are critical for effective error processing (Ridderinkhof, Ullsperger, Crone, \& Nieuwenhuis, 2004). Hypoactivation of these same regions and a reduced tendency to correct performance following errors have also been highlighted in a number of putatively frontal disorders including schizophrenia (Mathalon et al., 2002; Morris, Yee, \& Nuechterlein, 2006), obsessive-compulsive disorder (Ruchsow et al., 2005), substance abuse (Franken, van Strien, Franzek, \& van de Wetering, 2007) and attention-deficit hyperactivity disorder (ADHD) (e.g. BurgioMurphy et al., 2007; Rubia, Smith, Brammer, Toone, \& Taylor, 2005; Schachar et al., 2004). However, one area of uncertainty in this clinical work, is the explicit role played by conscious error awareness. Damage to the frontal lobes has been associated with decreased awareness of one's deficits including a tendency to 'miss' errors during neuropsychological tasks (McAvinue, O’Keeffe, McMackin, 
\& Robertson, 2005; O'Keeffe, Murray, et al., 2007). Reduced awareness of one's deficits predicts behavioural disturbances in brain injured populations (Prigatano \& Schachter, 1991) and may be tied to failures of goal-directed attention (O'Keeffe, Dockree, Moloney, Carton, \& Robertson, 2007; Shalgi, O'Connell, Deouell, \& Robertson, 2007). Consequently there is an imperative for studies to investigate whether reduced awareness might contribute to the self-monitoring deficits observed in other clinical populations. Here we examine the behavioural and electrophysiological correlates of error processing in adults with ADHD while distinguishing explicitly between errors made with and without conscious awareness.

ADHD is characterised by primary behavioural symptoms of inattention, impulsivity and hyperactivity (A.P.A., 2000). The high incidence of ADHD and controversy regarding the use of subjective behaviour reports in its diagnosis has directed research towards clarifying its biological bases and identifying core cognitive or physiological markers that could contribute to an objective diagnosis. Neuropsychological studies have convincingly demonstrated that these behavioural symptoms are attributable, at least in part, to an underlying executive dysfunction, including problems of response inhibition, working memory and aspects of attention (Seidman, 2006). Morphometric analyses have indicated subtle volumetric reductions of the prefrontal cortex and ACC in both children and adults with ADHD (Seidman, Valera, \& Makris, 2005; Sowell et al., 2003) while numerous functional imaging studies have reported decreased activation of these regions during the performance of a range of executive tasks (Bush, Valera, \& Seidman, 2005). However, executive control is typically assessed in terms of overall accuracy on a given task without consideration of differences in post-error behaviour. Since executive control is dependent on efficient error processing to signal the need for increased levels of attentional or cognitive resources, a basic failure to detect errors or a difficulty reacting to errors could be a separable and important component of neuropsychological task performance. Hence, the study of error processing and error awareness might reveal a novel basis for the broad profile of executive deficits in ADHD.

In recent years, electrophysiological research has isolated distinct neural signatures associated with error monitoring and error awareness thus affording a fine-grained analysis of error-related processing in ADHD than was possible previously. A growing number of recent ERP studies have investigated error-processing amongst children with ADHD and have pointed to abnormalities in two well established error-related components (Burgio-Murphy et al., 2007; Jonkman, van Melis, Kemner, \& Markus, 2007; Liotti, Pliszka, Perez, Kothmann, \& Woldorff, 2005; van Meel, Heslenfeld, Oosterlaan, \& Sergeant, 2007; Wiersema, Van der Meere, \& Roeyers, 2005). The first is the error-related negativity (ERN), a frontocentrally distributed negative wave seen approximately $100 \mathrm{~ms}$ following an erroneous response, while the second is the Error Positivity (Pe) which peaks $300-500 \mathrm{~ms}$ after an error and is maximal over centro-parietal regions. No studies have examined these components in adults with ADHD.

In their 2001 study, Nieuwenhuis and colleagues explored the extent to which the ERN and Pe are affected by error awareness. Using an antisaccade paradigm the authors demonstrated that the error-related negativity was equally present following errors that participants had or had not consciously perceived, but the Pe was only present if an error was consciously perceived. O'Connell et al. (2007) replicated these findings in the manual response modality. In O'Connell et al. (2007) participants performed a Go/No-Go response inhibition task that was specifically designed to assess levels of error awareness and it was noted that the Pe was preceded by an early positive deflection with a fronto-central maximum. No influence of error awareness was found for either the ERN or the early positivity but the Pe was only evident if participants were consciously aware of committing errors.
The ERN has been the subject of intense investigation within the error processing field and convergent lines of evidence suggest that its generator lies in a dorsal region of the ACC (Brazdil, Roman, Daniel, \& Rektor, 2005; Herrmann, Rommler, Ehlis, Heidrich, \& Fallgatter, 2004; Van Veen \& Carter, 2002). Since an ERN-like component, known as the correct-response negativity (CRN), is also evident on correct Go trials there is growing consensus that, rather than detecting errors per se, the ERN indexes performance monitoring processes that are continuously active throughout task duration but enhanced on erroneous trials (Vidal, Hasbrouc, Grapperonc, \& Bonnet, 2000). This view seems to fit with recent evidence that, rather than detecting errors themselves, the primary role of the ACC may be to continually monitor performance in order to identify changes in error likelihood (Brown \& Braver, 2005 but see also Nieuwenhuis, Schweiser, Mars, Botvinick, \& Hajcak, 2007) or outcome value (Holroyd, Niuwenhuis, Mars, \& Coles, 2004). Although it is apparently dependent on error awareness, far less is known about the precise functional significance of the Pe. A recent review by Overbeek, Nieuwenhuis, and Ridderinkhof (2005) highlights that there is evidence to support a number of hypotheses (originally proposed by Falkenstein, 2004) including the initiation of behavioural adaptation, neuroaffective processing, or a P3-like evaluation of the error event as well as the possibility that the Pe directly reflects error awareness or processes leading to error awareness.

The latest ERP evidence therefore indicates that the human error processing system possesses distinct pre-conscious and conscious detection mechanisms. As such, the ERN, early positivity and Pe can provide useful markers for investigating the time-course of error monitoring difficulties while also distinguishing between unconscious and conscious processing. Nevertheless, an important message that emerges from this past work is that the Pe, although dependent on error awareness, does not necessarily provide a direct measure of error awareness. This distinction is particularly important in the context of clinical studies in which Pe abnormalities could potentially emerge because fewer errors have reached awareness, or because there is a difference in the processing of detected errors or even a combination of both possibilities. While previous ERP studies in ADHD have provided good evidence to suggest that error processing is disrupted (Burgio-Murphy et al., 2007; Jonkman et al., 2007; Liotti et al., 2005; van Meel et al., 2007; Wiersema et al., 2005), the role that error awareness plays in this disruption can only be fully elucidated through the inclusion of an explicit measure of error awareness.

The present study constitutes an extensive electrophysiological investigation of error processing in adults with ADHD. Eighteen adults diagnosed with ADHD performed the Error Awareness Task (EAT, Hester, Foxe, Molholm, Shpaner, \& Garavan, 2005) and were compared to a group of 21 matched controls. ERP measures were acquired from 14 participants with ADHD and 12 control participants in order to verify pre-conscious and conscious aspects of error processing. Measures of electrodermal activity (EDA) were also acquired during task performance. EDA is a measure of autonomic arousal commonly used as an index of psychophysiological responsiveness to motivationally significant events (Dawson, Schell, \& Filion, 2000). Investigations of the cortical influences on EDA have indicated that prefrontal regions play a central role in integrating motivationally important information with adaptive changes in bodily states of arousal (Critchley et al., 2003).

\section{Methods}

\subsection{Participants}

Eighteen outpatient adults diagnosed with the combined subtype of ADHD and 21 controls matched for age, sex (one female) and handedness (one left-handed) participated in this study. The two groups had comparable IQ scores as measured by the vocabulary and block design subtests of the Wechsler Adult Intelligence Scale III and 
Table 1

Summary of demographic data for adult ADHD and control groups. Wender Utah Rating Scale (WURS) and Conners Adult ADHD Rating Scale (CAARS) measures are reported as the average of the self and observer report scores for each participant.

\begin{tabular}{|c|c|c|c|c|}
\hline & $\begin{array}{l}\text { Adult ADHD } \\
\text { Mean (SD) }\end{array}$ & $\begin{array}{l}\text { Control } \\
\text { Mean (SD) }\end{array}$ & $F(1,37)$ & $P$ \\
\hline$N$ & 18 (2 female) & 21 (1 female) & & \\
\hline Age & $23.7(5.1)$ & $22.0(2.9)$ & 1.7 & 0.2 \\
\hline Estimated IQ & $108(10.5)$ & $113(11)$ & 2.5 & 0.12 \\
\hline Years 2nd level education & $4.9(0.3)$ & $5(0)$ & 2.5 & 0.12 \\
\hline Years 3rd level education & $1.6(1.1)$ & $2.3(1.2)$ & 3.5 & 0.07 \\
\hline WURS (raw score) & $63.2(12.1)$ & $27.8(13.9)$ & 59.4 & $0.001^{* * *}$ \\
\hline $\begin{array}{l}\text { CAARS DSM-IV } \\
\text { inattention }(\mathrm{T})\end{array}$ & $76.3(6.6)$ & $51.1(7.2)$ & 108.3 & $0.001^{* * *}$ \\
\hline $\begin{array}{l}\text { CAARS DSM-IV } \\
\text { hyperactivity (T) }\end{array}$ & $72.1(10.1)$ & $50.0(7.9)$ & 46.9 & $0.001^{* * *}$ \\
\hline
\end{tabular}

denotes significance $<0.001$.

were also matched for years of second and third level education. The demographic data for the two participant groups are summarised in Table 1. All participants had normal or corrected-to-normal vision. Patients were withdrawn from any stimulant medication $36 \mathrm{~h}$ prior to testing. All participants gave written informed consent and all procedures were approved by the ethical review boards of St Vincents Hospital, Fairview and the School of Psychology, Trinity College Dublin.

\subsection{Recruitment and screening}

An experienced psychiatrist who specialises in child and adult ADHD (MF) made the initial diagnosis. Patients volunteered for the present study following a telephone call or mail advertisement. Detailed investigation of current symptom levels as well as a retrospective assessment of childhood symptoms was undertaken. To achieve a retrospective diagnosis of ADHD in childhood, patients must have met 6 of 9 DSMIV criteria for inattention or for hyperactivity/impulsivity. To achieve a diagnosis in adulthood, each patient must have met 6 of 9 criteria on either axis at the time of assessment. Additionally, each patient had to report persistent ADHD symptoms from childhood to adulthood and to have experienced moderate to severe levels of impairment across a range of different settings attributable to the symptoms of ADHD.

Nine patients were currently taking psychostimulant medication, four had taken stimulant medication in the past but had stopped and five were stimulant-naive. Controls were recruited via poster advertisements and all participants received $€ 32$ as a defrayal of expenses. Before inclusion in the study all participants were screened with a telephone interview addressing personal and family history of ADHD, learning disability, psychiatric, neurological or medical disorders, use of medication and substance abuse. Also, prior to testing all participants completed the Conners' Adult ADHD Rating Scale (CAARS, (Conners, Erhardt, \& Sparrow, 2003)) and the Wender Utah Rating Scale (WURS), a retrospective measure of ADHD symptoms in childhood (Ward, Wender, \& Reimherr, 1993). The observer versions of both scales were also administered to a close family member or partner. Finally, the Standard Clinical Interview for DSM-IV (SCID) was administered by a trained psychiatrist (AL) to all clinical participants in order to assess Comorbid Axis I disorders (Spitzer, Williams, Gibbon, \& First, 1992). Comorbid Axis I disorders in the patient group included lifetime depression $(N=1)$, current depression $(N=1)$, bipolar disorder $(N=1)$, current anxiety disorder $(N=1)$ and substance abuse $(N=4$, alcohol and cannabis use). Three control participants were taking cannabis recreationally.

\subsection{Exclusion criteria}

Participants were excluded if they reported any previous history of psychosis (or if psychosis was indicated by SCID interview), organic brain disorder, epilepsy, serious head injury or learning disability. Controls were only included if they had no family history of ADHD and if they themselves were not suspected of having ADHD based on the screening tests. The cut-off for inclusion of controls was an average self and other rated T-score of less than 65 (95th percentile) on each of the three DSM-IV symptom subscales of the CAARS and an average self and other rated score of less than 36 on the WURS. A cut-off score of higher than 36 on the WURS has been found to correctly identify $96 \%$ of adults with ADHD and $96 \%$ of normal participants (Ward et al., 1993). The ADHD group was required to have an average self and other rated T-score greater than 65 on two of the three DSM-IV CAARS subscales and average self and other rated score of more than 36 on the WURS (these scores are summarised in Table 1).

\subsection{Error Awareness Task}

We used a validated error awareness paradigm developed by Hester et al. (2005). The Error Awareness Task (see Fig. 1) is a motor Go/No-Go response inhibition task in which participants are presented with a serial stream of single colour words with congruency between the word and its font colour manipulated. Participants were trained to respond to each of the words with a single 'Go trial' button press and to withhold this response when either of two different circumstances arose. The first circumstance occurred if a word and its font colour were repeated on two consecutive trials (Repeat No-Go), and the second circumstance occurred if the word and its font colour did not match (Incongruent No-Go). These two competing NoGo conditions were introduced to increase the likelihood that some errors would go unnoticed. In the event of a commission error (failure to withhold to either of these No-Go scenarios) participants were trained to press a second 'awareness button' on the subsequent trial and to forego the standard Go response. All NoGo stimuli were followed by at least four Go stimuli since making the awareness response might have disturbed processing of the stimuli immediately following an error. Six different colour words (Red, Blue, Green, White, Yellow, Purple) and font colours were used. Participants were instructed to time their response to the offset of each stimulus. This kind of 'response-locking' has been shown to reduce interindividual variability and to limit the extent to which impulsive response styles might contribute to performance deficits (Stuss, Murphy, Binns, \& Alexander, 2003). Participants performed the task in a dimly lit, sound-attenuated, electrically shielded room. All participants were well practiced and understood the requirements of the task.

Each EAT block consisted of 225 stimuli comprising 200 Go stimuli and 25 No-Go stimuli. Across 8 blocks each participant received 100 Repeat No-Go trials and 100 Incongruent No-Go trials. All stimuli were presented for $600 \mathrm{~ms}$ followed by an interstimulus-interval (ISI) of $900 \mathrm{~ms}$. All stimuli appeared $0.25^{\circ}$ above a white fixation cross (continuously displayed throughout the task) on a grey background at a viewing distance of approximately $150 \mathrm{~cm}$. Participants were instructed to focus on the fixation cross during the task in order to minimise eye movements. All participants with ADHD completed 8 experimental blocks of the EAT. However, to maximise the number of errors for ERP averaging, control participants completed an average of 11.2 blocks of the EAT (range 8-14). If participants had made over 30 errors after 8 blocks then testing was terminated. Testing was also terminated if participants did not commit at least 20 errors of each kind after 14 blocks.

\subsection{EEG data acquisition}

Continuous EEG was acquired through the ActiveTwo Biosemi ${ }^{\mathrm{TM}}$ electrode system from 72 scalp electrodes, digitized at $512 \mathrm{~Hz}$ with an open pass-band from DC to $150 \mathrm{~Hz}$. With the BioSemi system, every electrode or combination of electrodes can be assigned as the reference, and this is done purely in software after acquisition. A detailed description of the referencing and grounding conventions used by the BioSemi active electrode system appears online (http://www. biosemi.com/faq/cms\&drl.htm). Vertical eye movements were recorded with two VEOG electrodes placed below the left and right eye, while HEOG electrodes at the outer canthus of each eye recorded horizontal movements. Data were analysed using BESA Version 5.1 (Brain Electric Source Analysis) software (www.besa.de).

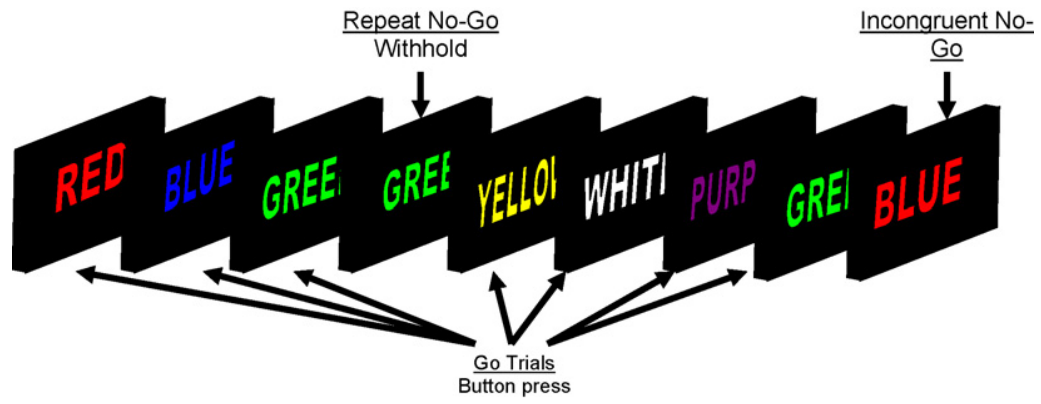

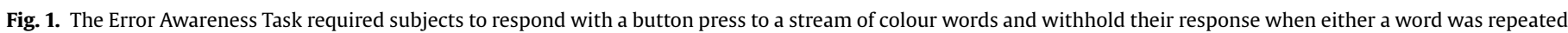
on consecutive trials or the font and word were incongruous. Subjects were trained to press a different button following any commission errors. 


\subsection{Analysis of physiological data}

For analysis and display purposes, data were average referenced and filtered with a $30 \mathrm{~Hz}$ low-pass filter ( $48 \mathrm{~dB} /$ octave) and a $0.5 \mathrm{~Hz}$ high-pass filter ( $6 \mathrm{~dB} /$ octave). Response-locked data were segmented into epochs of $400 \mathrm{~ms}$ before to $500 \mathrm{~ms}$ after response and baseline-corrected relative to the interval -400 to $-200 \mathrm{~ms}$. All electrode channels were subjected to an artefact criterion of $\pm 100 \mu \mathrm{V}$ from -400 to $+500 \mathrm{~ms}$ to reject trials with excessive EMG or other noise transients. The single trial EEG signals were also corrected for EOG artefacts by means of an eye movement correction procedure developed by Berg and Scherg (1994). Accepted ERP trials were averaged separately for correct Go responses, aware errors and unaware errors ( since correct withholds involve no response these trials could not be included in this analysis). For the analysis of physiological data, commission errors to the Repeat No-Go and Incongruent No-Go stimuli were combined. The number of single trial ERPs included for averaging was equated across error conditions (aware error vs. unaware) for each participant by a process of random exclusion, implemented by BESA software, to ensure equivalent signal-to-noise ratios. Following this step the number of sweeps entered into each error condition was compared for the $\mathrm{ADHD}$ and control groups and it was found that the number of trials entered were also statistically comparable across groups. To maximise signal-to-noise ratios, no further trials were excluded. An average of $69.4(\mathrm{SD}=43.8)$ aware error trials and $37.0(\mathrm{SD}=15.4)$ unaware error trials were included in the control group versus 54.0 $(\mathrm{SD}=15.4$ ) aware trials and 35.0 (14.8) unaware trials in the ADHD group (aware comparison, $F(1,25)=1.7, p=0.2$; unaware comparison, $F(1,25)=0.1, p=0.7)$. The ERN was defined as the most negative peak at $\mathrm{FCz}$ occurring in a window from 50 to $120 \mathrm{~ms}$ post-response. The early positivity, immediately following the ERN, was measured as the most positive peak at $\mathrm{FCz}$ between 140 and 240 ms post-response. Finally, because the $\mathrm{Pe}$ is a more sustained component, the mean amplitude at $\mathrm{CPz}$ between 300 and $500 \mathrm{~ms}$ post-response was used.

Source localisation was conducted on the grand-average, average-referenced waveforms of each group by BESA 5.1 using a four-shell spherical head model approximation. Free-fit dipole source modelling was implemented for the $20 \mathrm{~ms}$ interval around the peaks of the ERN and early positivity while an interval of 300-500 postresponse was used for the Pe. Source localisation of the ERN and early positivity was conducted on aware error ERP waveforms. The sources of the Pe were first modelled using the aware error waveforms and then verified using a difference waveform in which unaware error ERPs were subtracted from aware error ERPs. The source analysis results for the present control group were calculated in the same manner and have been previously reported (O'Connell et al., 2007). Here the same model was used to provide a baseline comparison for the adult ADHD group. The remaining, un-modelled variance for each ERP component was calculated using measures of residual variance (RV) and peak explained variance (Best) within the selected ERP interval providing an indication of the validity of the source model.

To investigate whether the two participant groups differed in their motivational sensitivity to errors, EDA was recorded. EDA measurements were taken from all participants during behavioural testing with a 5 channel BIOPAC MP30B unit and two $\mathrm{Ag} / \mathrm{AgCL}$ finger electrodes. Peak-to-peak skin conductance responses (SCRs) were measured within the latency window of $0.05-4.5 \mathrm{~s}$ post No-Go stimulus and averaged separately for each of three No-Go response types: correct inhibitions, aware errors and unaware error. It was possible to include correct inhibitions in the present analysis since SCR averaging was time-locked to No-Go stimulus onset. Correct inhibitions were included in order to assess whether possible differences in autonomic responsiveness were specific to errors. Go stimuli were not included in this analysis as the frequency of their occurrence leads to habituation of the SCR preventing any meaningful group comparison. Due to technical difficulties EDA data were analysed for only 19 of the Control participants and 15 of the ADHD participants.

\subsection{Statistical analysis}

Since the control group completed a greater numbers of EAT blocks to maximise trials for ERP averaging, behavioural performance was compared over the first 8 blocks of testing as this was the minimum number of blocks completed all participants. Variables analysed included percentage commission errors (commission errors/total No-Go trials $\times 100$ ), percentage omission errors (omission errors/total Go trials $\times 100$ ). Error awareness was derived by dividing the number of aware commission errors by the total number of commission errors. Hence, this measure tells us what percentage of commission errors participants had consciously detected. Variability of reaction time for correct Go responses (GoRT) was calculated as the average standard deviation of GoRT per block per participant. Go trials for which participants responded with the awareness button were excluded from these analyses. Correlations between error awareness and key behavioural measures and symptom severity were analysed. To avoid type-I error, Bonferroni corrections were applied using a 0.05 alpha-level for each family of comparisons. To ensure a clean signal, only those participants who made at least 20 aware and 20 unaware errors were included in the ERP analysis. This led to a reduced sample of 12 controls and 14 participants with ADHD. The peak amplitudes of the ERN, error positivity and Pe were analysed as a function of Group (ADHD vs. controls) and Response Type (correct Go press vs. aware errors vs. unaware errors). A portion of the control data has been presented elsewhere in a paper examining the ERP signatures of error awareness (O'Connell et al., 2007).
Table 2

EAT performance data for adult ADHD and control groups.

\begin{tabular}{lcccl}
\hline & $\begin{array}{l}\text { Adult ADHD } \\
\text { Mean (SD) }\end{array}$ & $\begin{array}{l}\text { Control } \\
\text { Mean (SD) }\end{array}$ & $F(1,37)$ & $P$ \\
\hline$N$ & 18 & 21 & & \\
Errors of commission & $52.8 \%(19.6)$ & $30.72 \%(16.6)$ & 14.2 & $0.001^{* * *}$ \\
Errors of omission & $1.45 \%(1.23)$ & $0.5 \%(0.61)$ & 9.1 & $0.005^{* *}$ \\
Error awareness & $62.9 \%(19.8)$ & $75.8 \%(14.7)$ & 5.2 & $0.028^{*}$ \\
Mean Go RT & $607.8(108.6)$ & $625.4(79.2)$ & 0.34 & 0.5 \\
Mean Go RT variability & $128.06(47.69)$ & $96.87(31.6)$ & 5.4 & $0.02^{*}$ \\
Mean aware error RT & $553.0(104.5)$ & $597.6(110.8)$ & 1.6 & 0.2 \\
Mean unaware error RT & $657.4(107.5)$ & $707.1(175.9)$ & 1.1 & 0.3 \\
\hline
\end{tabular}

denotes significance $<0.05$.

* denotes significance $<0.01$.

*** denotes significance $<0.001$.

\section{Results}

\subsection{Behavioural data}

The means, standard deviations and significance levels for performance data are presented in Table 2. The adult ADHD group made significantly more inhibition errors (errors of commission) relative to the matched controls. ADHD participants also made significantly more errors of omission (failing to press on a Go stimulus) and exhibited significantly greater variability of RT. There were no group differences in Mean GoRT on correct Go trials, aware errors or unaware errors confirming that both participant groups had successfully timed their responses to stimulus-offset. In addition to this apparent response inhibition deficit, adult ADHD participants were consciously aware of a significantly smaller percentage of their errors.

The EAT paradigm is not well optimised to look at post-error slowing due to the requirement to press the second 'awareness' button immediately after a consciously detected error. Switching to the awareness button and then switching back to the Go button leads to abnormally slow RTs to the next two Go stimuli. Since the 'awareness' response does not occur on unaware trials we used the third RT after a target to calculate post-target corrective slowing (see Fig. 2). A repeated-measures ANOVA was conducted including factors of RT slowing (RT immediately preceding the error vs. third RT after the target), Target Response (correct withhold, aware error,

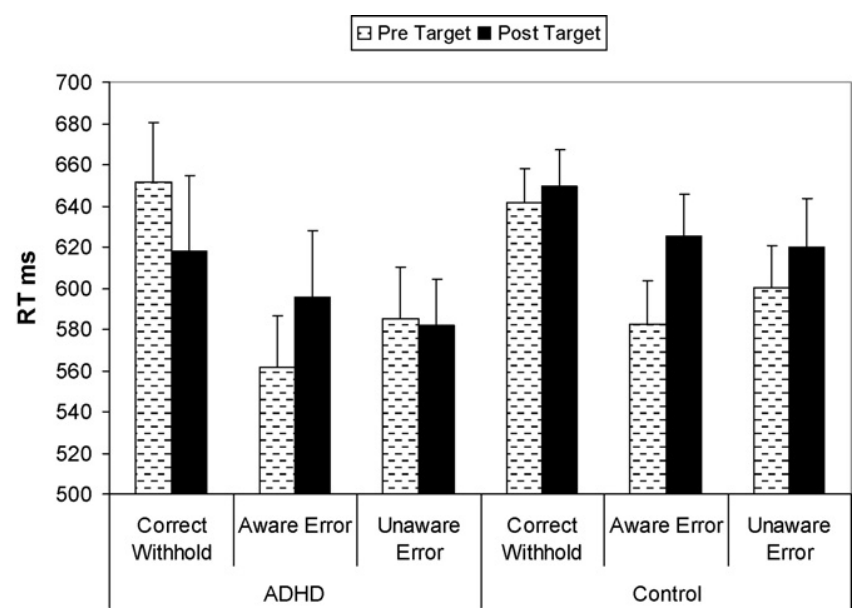

Fig. 2. Mean RT pre- and post-target stimuli analysed as a function of Target Response (correct withhold, aware error, unaware error) and Group. Due to the requirement to press a second 'awareness' button immediately after an error, the post-target RT measure was calculated using the third response after a target trial. Significant RT slowing was only seen following an aware error and was not seen after either a correct withhold or unaware error. There were no significant group differences on these measures. 
unaware error), and Group (ADHD vs. Control). The results indicated significant main effects of RT slowing, $F(2,72)=7.7, p=0.01$, and Target Response, $F(2,72)=25.6, p=0.001$, and a Target Response by RT slowing interaction, $F(2,72)=5, p=0.01$. There were no significant Group differences (all $p>0.1$ ). Post-hoc contrasts indicated that the Target Response effect was driven by slower RTs in the withhold condition relative to the two error conditions (both $p<0.05$ ). In addition, RTs were significantly faster for aware errors than for unaware errors $(p<0.05)$. Post-hoc $t$-tests with Bonferroni corrections indicated that significant post-target slowing was only seen following an aware error $(p<0.01)$ and was not seen following a correct withhold $(p=0.9)$ or an unaware error $(p=0.5)$. These results suggest that post-error correction of response time only occurred if the error was consciously detected but there did not appear to be any distinction between the two groups in this regard. The fact that we were unable to analyse the immediate post-target RT could have diluted any potential group effects.

Further analyses were conducted to examine whether differences in the difficulty of the two No-Go target conditions (repeat vs. incongruent) might have affected error awareness. Both participant groups made more errors on Incongruent NoGos (control mean $=37.5 \%, \mathrm{SD}=16.7$; $\mathrm{ADHD}$ mean $=58.6 \%, \mathrm{SD}=19.9$ ) relative to Repeat No-Gos (control mean $=23.9 \%, \mathrm{SD}=18.3$; ADHD mean $=46.7 \%, S D=21.5$ ). A repeated-measures ANOVA confirmed this difference with a significant main effect of No-Go type (repeat vs. incongruent), $F(1,37)=45.39, p<0.001$, but there was no Group by No-Go type interaction, $F(1,37)=0.21, p=0.65$. In contrast to the distribution of total commission errors, however, there was no significant main effect of No-Go type on the number of unaware errors, $F(1,37)=1.6, p=0.2$, and no Group by No-Go type interaction, $F(1,37)=0.2, p=0.6$. The absence of No-Go type by Group interactions indicates that our between-groups behavioural and ERP differences for error awareness are not confounded by differences in the difficulty of the two No-Go target conditions. Finally, we observed no correlation between estimated IQ score $(r=0.11, p=0.5)$.

Although $5 \mathrm{~min}$ breaks were allowed in between blocks to offset fatigue the possibility that differential time-on-task effects could account for this group difference was investigated by plotting awareness as a function of testing block. There was a significant main effect of Block, $F(1,37)=2.25, p<0.05$, but no Group by Block interaction, $F(1,37)=0.462, p=0.86$, and tests of within-subjects effects indicated that the main effect of Block was driven by a significant linear trend, $F(1,37)=6.47, p<0.05$. Thus error awareness did decline with time-on-task but there were no group differences in this regard.

Separate bivariate correlations indicated no relationship between awareness rates and commission errors in either group suggesting that these are dissociable aspects of executive control (controls, $r=-0.178, p=0.44$; ADHD, $r=0.044, p=0.86$ ). Further bivariate correlations within the ADHD group indicated that there was a significant relationship between awareness rates and errors of omission $(r=-0.66, p<0.0063)$ and GoRT variability $(r=-0.615$, $p<0.0063$ ). Thus, an increased rate of conscious error detection was associated with a decreased number of omission errors and reduced GoRT variability. In the ADHD group, errors of commission were not correlated with either errors of omission $(r=0.2$, $p=0.3$ ) or GoRT variability $(r=0.3, p=0.3)$. None of these relationships reached significance in the control group (error awareness and errors of commission, $r=-0.2, p=0.4$; error awareness and errors of omission, $r=-0.3, p=0.2$; error awareness and Go RT variability, $r=-0.18, p=0.4$ ).

Finally the relationship between individual error awareness rates on the EAT and current self-reported symptom severity on the 7 axes of the CAARS (inattention/memory problems, impulsivity/emotional lability, hyperactivity, self-concept, DSM-inattention, DSM-hyperactivity/impulsivity, DSM total symptoms, ADHD index)
Table 3

EAT performance data for adult ADHD and control ERP subgroups.

\begin{tabular}{lccll}
\hline & $\begin{array}{c}\text { Adult ADHD } \\
\text { Mean (SD) }\end{array}$ & $\begin{array}{l}\text { Control } \\
\text { Mean (SD) }\end{array}$ & $F(1,24)$ & $P$ \\
\hline$N$ & 14 & 12 & & \\
Age & $23.3(3.7)$ & $21.4(2.5)$ & 2.5 & 0.13 \\
Estimated IQ & $107(10.7)$ & $113(11)$ & 1.90 .17 & \\
Errors of commission & $54 \%(2.0)$ & $39.6 \%(16)$ & 3.9 & 0.06 \\
Errors of omission & $1.5 \%(1.3)$ & $0.5 \%(0.6)$ & 5.3 & $0.03^{*}$ \\
Error awareness & $63 \%(14)$ & $73 \%(12)$ & 4.1 & 0.056 \\
Mean Go RT & $611(114)$ & $636(87)$ & 0.4 & 0.6 \\
Mean Go RT variability & $129.9(48)$ & $111.5(32)$ & 1.3 & 0.27 \\
Mean aware error RT & $560(103)$ & $601(131)$ & 0.8 & 0.4 \\
Mean unaware error RT & $653(110)$ & $663(100)$ & 0.05 & 0.8 \\
\hline
\end{tabular}

denotes significance $<0.05$.

was investigated. A partial correlation, controlling for the effect of Group $(N=39)$, indicated significant relationships between error awareness and self-reported impulsivity/emotional lability $(r=-0.47, p<0.0063)$, self-concept $(r=-0.47, p<0.063)$ and the ADHD index (a measure of general ADHD risk) $(r=-0.59$, $p<0.0063$ ). The direction of these correlations indicated that participants with higher levels of symptomatology in these domains have poorer awareness of their errors.

\subsection{Event-related potentials}

Because a reduced sample of participants was included in the ERP analyses further comparisons were conducted to verify that the two ERP sub-groups were matched for basic demographic variables and demonstrated behavioural performance on the EAT that was representative of the group as a whole. The means, standard deviations and significance levels for these comparisons are presented in Table 3 and confirm that the ERP sub-groups remained matched for age and IQ and that behavioural differences on the EAT remained in the same direction as presented in Table 2 .

Fig. 3 displays ERPs elicited by correct Go responses, aware errors and unaware errors at $\mathrm{FCz}$ and $\mathrm{CPz}$ for each group. For the ERN, measured over $\mathrm{FCz}$, there was a significant main effect of Response Type on amplitude, $F(2,48)=4.48, p<0.05$, but no main effect of Group, $F(1,24)=2.57, p=0.12$, and no Response Type by Group interaction, $F(2,48)=0.4, p=0.6$. Post-hoc analysis with Bonferroni corrections of the main effect of Response Type revealed that the ERN amplitude was largest following an error but did not differ as a function of error awareness (Go vs. aware $p<0.01$; Go vs. unaware $p<0.05$; aware vs. unaware $p=0.997)$.

A clear Group difference was apparent in the amplitude of the early positivity $(140-240 \mathrm{~ms}), F(1,24)=7.1, p<0.05$. Bonferronicorrected $t$-tests indicated that controls and ADHD participants differed in the amplitude of the early positivity across all three conditions; Go $(p<0.05)$, aware $(p<0.05)$ and unaware $(p<0.05)$. There was neither a main effect of Response Type, $F(2,48)=3.1, p=0.06$, nor an interaction of Response Type and Group, $F(2,48)=0.7, p=0.5$.

For the amplitude of the Pe, measured at $\mathrm{CPz}$, there was a significant main effect of Response Type, $F(2,48)=49.3, p<0.001$, and a significant Group by Response Type interaction $[F(2,48)=6.15$, $p<0.01$ ] but no main effect of Group, $F(1,24)=2.1, p=0.15$. Post-hoc analysis with Bonferroni corrections indicated that, for both groups, the amplitude of the Pe was significantly larger for aware errors relative to both unaware errors (controls $p<0.001$, ADHD $p<0.01$ ) and correct Go responses (controls $p<0.001$, ADHD $p<0.001$ ). No amplitude difference was found for unaware errors or correct Go responses in either group (controls $p=1$, ADHD $p=0.5$ ). Further post-hoc comparisons indicated that the control, relative to the ADHD group, had significantly larger Pe amplitudes on aware errors $(p<0.01)$ but there were no amplitude differences for correct Go presses $(p=0.89)$ or unaware errors $(p=0.37)$. 
(A)
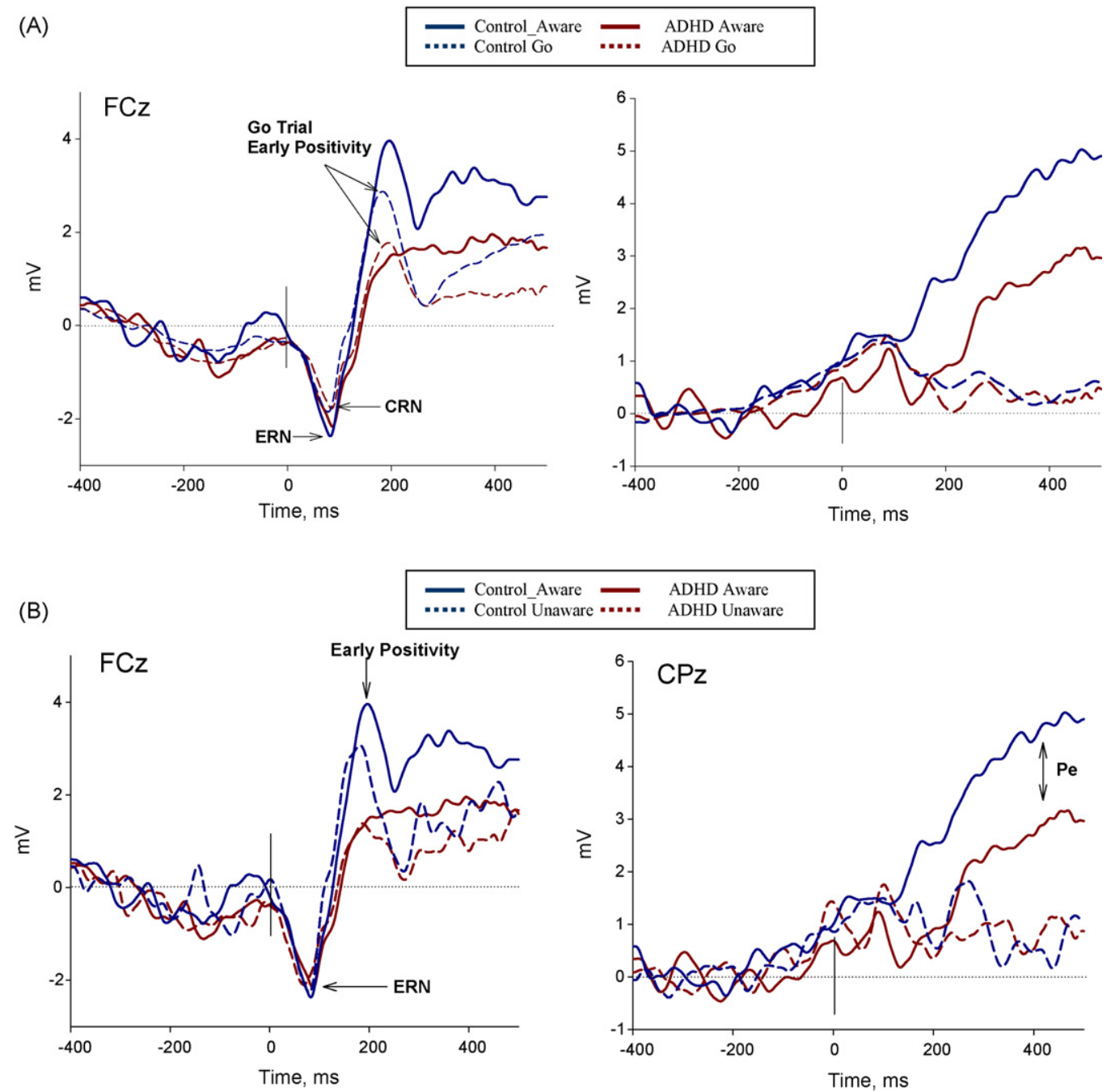

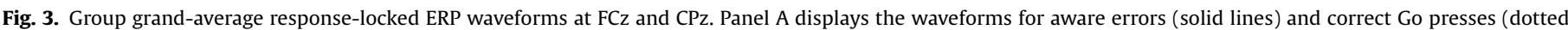

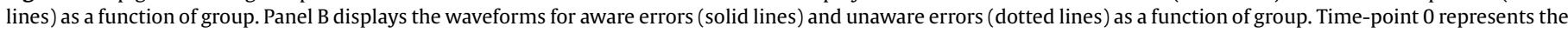

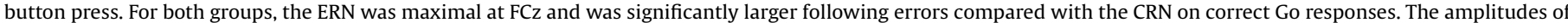

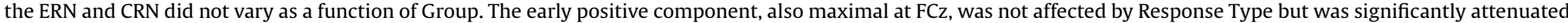

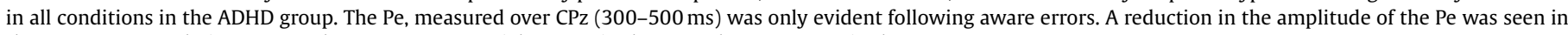
the ADHD group, relative to controls, on aware error trials. $N=12$ in the control group, $N=14$ in the ADHD group.

\subsection{Source analysis}

To investigate the functioning of key error processing regions in the ADHD group, free-fit source localisation using BESA 5.1 was conducted, thereby placing no restrictions on the possible source locations for the ADHD group. In a previous study using the same control group data, source analysis indicated a dorsal ACC source for both the ERN and early positivity and separate ACC and posterior cingulate/precuneus sources for the Pe (O'Connell et al., 2007). The present study employed the same step-wise method of source analysis to locate the generators of the three error-related ERPs for the adult ADHD group. The resulting model included a single generator that accounted for most of the variance in the ERN ( RV $=16 \%$, Best $=13.4 \%)$ and early positivity $(\mathrm{RV}=11.8 \%$, Best $=11 \%)$ and was located in the region of the dorsal ACC $(x=-18, y=-2, z=42)$. As can be seen in Fig. 4, this source is very close to the one indicated for the ERN/early positivity of the control group $(x=-15, y=00, z=45)$. The same source location was indicated when using the unaware error waveform.

The Pe of the ADHD group was also modelled using a single source, this time located around the posterior cingulate and pre- cuneus (RV 6.5\%, Best $4.2 \%, x=-4, y=-44, z=37$ ). Again a source in a very similar region to that previously indicated for the control group Pe was found $(x=-5, y=-38, z=40)$.

The most obvious difference between the Pe source models for the ADHD and control groups is that no ACC source was indicated for the Pe in the ADHD group. To confirm this finding we took the coordinates of the anterior ACC source for the control group ( $x=2.9, y=20.5, z=42.5$ ) and seeded a dipole in the same location for the ADHD group which was then optimised for orientation. The source models for each group, which in the case of the ADHD group included the seeded dipole, were then applied to the ERPs of individual participants within that group and separate grand-average source waveforms were generated. Fig. 5 displays the source waveform for the seeded anterior ACC source of the ADHD group. Statistical analysis of the posterior cingulate and anterior ACC source waveforms of both groups (mean nAmp 300-500 ms post-response) indicated a significant group difference in ACC activity at the latency of the Pe, $F(1,24)=11.3, p=0.003$, but no group differences at the same latency for the posterior cingulate source, $F(1,24)=0.05, p=0.8$. Thus the attenuation of the Pe in the ADHD group appears to be accounted for by reduced activity in the ACC. 

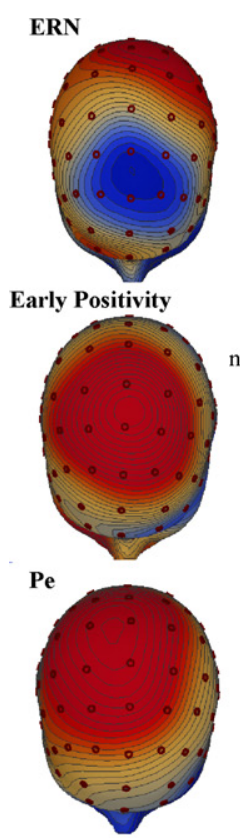
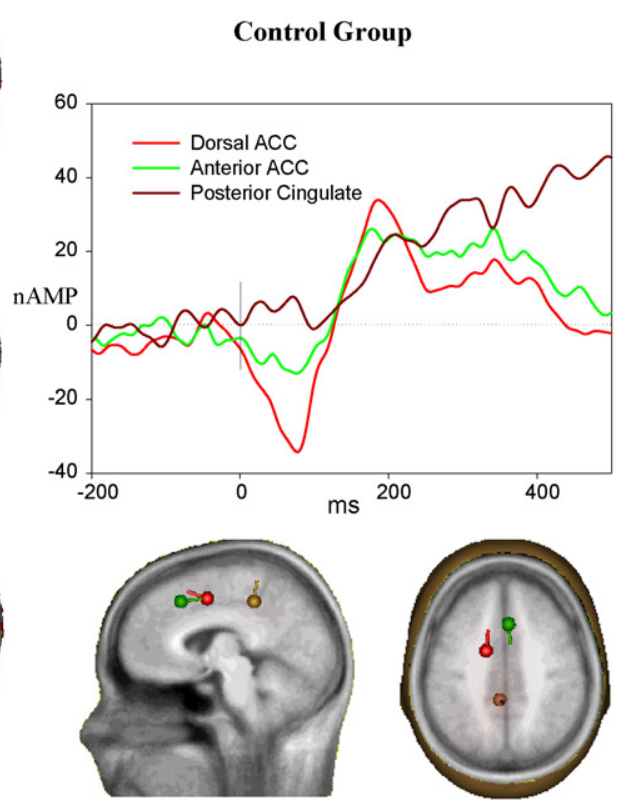
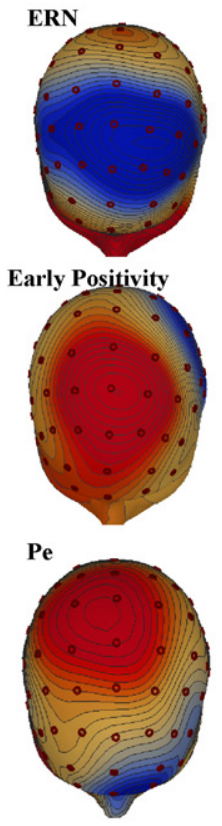

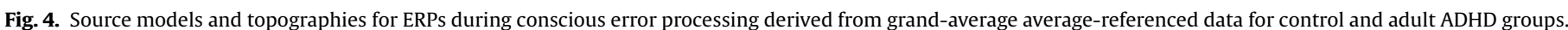

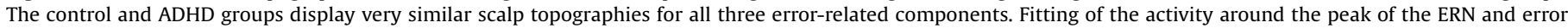

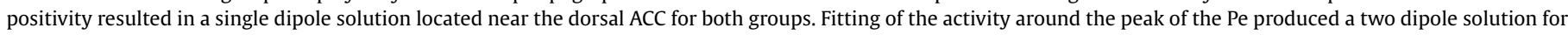
the control group and a single dipole solution for the ADHD group. No anterior ACC generator was indicated for the ADHD group.

\subsection{Electrodermal activity}

Mean skin conductance response amplitudes were analysed as a function of Response Type and Group and are displayed in Fig. 6 below. There were main effects of Response Type, $F(2,64)=6.59$, $p<0.01$ and Group, $F(1,32)=5.9, p<0.05$, but no interaction between these factors, $F(2,64)=0.915, p=0.414$. Hence, participants in the ADHD group showed an attenuated autonomic response to correct and incorrect No-Go responses.

\section{Discussion}

The present experiment provides the first direct evidence that adults with ADHD are less aware of their action errors than matched

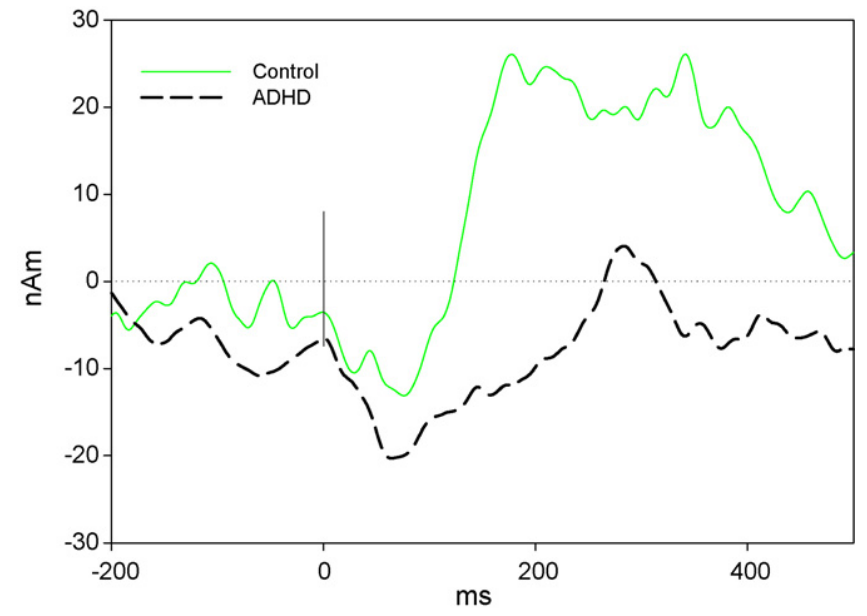

Fig. 5. The solid line displays the activity associated with the aware error waveforms for the control group that is accounted for by the anterior ACC source. The dashed black line displays the same activity for the ADHD group when a dipole is seeded in the same ACC region. The markedly reduced activity in the ADHD source waveform $300-500 \mathrm{~ms}$ post-response is consistent with the initial source model indicating an absence of an ACC contribution to the Pe in ADHD. controls. The performance data show that the ADHD group made significantly more errors of commission on the Error Awareness Task in keeping with previous work highlighting response inhibition deficits in this disorder (Lijffijt, Kenemans, Verbaten, \& van Engeland, 2005). Controlling for the total number of errors made by each participant, it was found that the ADHD group was aware of a significantly smaller portion of their errors than controls. These differences were not attributable to differential time-on-task effects arising from fatigue or reduced compliance and group differences were stable across the whole testing session. The correlation between decreased error awareness and increased symptom severity suggests that this study identifies a novel and potentially important neuropsychological phenotype for ADHD.

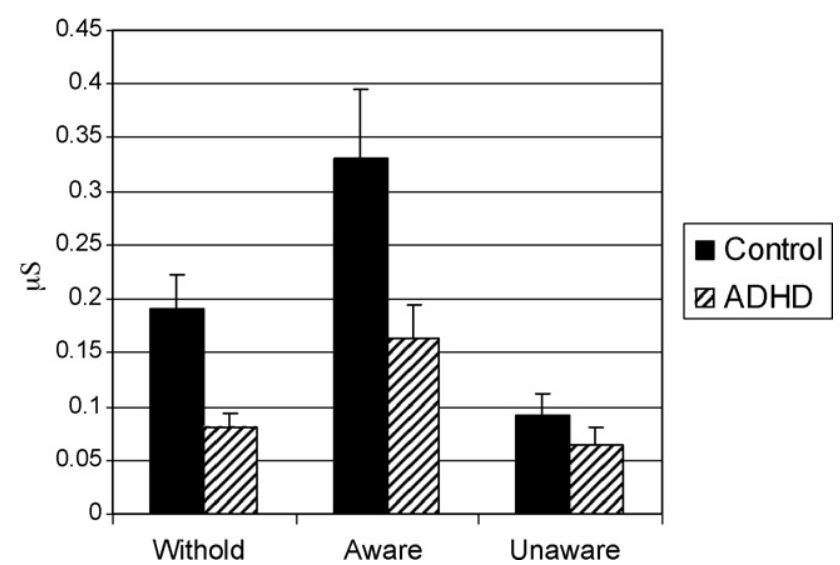

Fig. 6. Mean SCR as a function of Response Type (correct inhibition vs. aware errors vs. unaware errors) for ADHD and control groups. Both participant groups show strong phasic arousal responses when they are aware that they have made an error but this response is highly attenuated when an error is made without conscious awareness. The ADHD group exhibits significantly smaller arousal responses to correct and incorrect No-Go responses indicating a reduced autonomic responsiveness to salient task events. $N=19$ in the control group, $N=15$ in the ADHD group. 
Although the study of error awareness in the context of action monitoring is a relatively new area of research, there is evidence to suggest that error awareness may vary according to the background level of goal-directed attention. That is, an error will only be detected consciously if the participant is in a sufficiently attentive state such that contextually appropriate stimulus-response or goal mappings are highly activated. In a study by O'Keeffe, Murray, et al. (2007) and O'Keeffe, Dockree, et al. (2007) patients with traumatic brain injury consistently indicated awareness of errors on a test of response inhibition, whereas they were more frequently unaware of errors they made on a test of sustained attention. A recent study by Shalgi et al. (2007), which also used the EAT, found that increasing the level of task monotony by asking participants to time their responses to a regular post-stimulus cue, had opposite effects on response inhibition and error awareness rates, producing an improvement in the former but a deterioration in the latter. Although we cannot accept the null hypothesis, the present study found no correlation between error awareness rates and commission errors on the EAT suggesting that response inhibition and awareness deficits may arise from distinct neuropsychological processes in ADHD.

Interestingly, error awareness rates in our ADHD group were significantly correlated with response time variability and errors of omission. Poorer response time variability is a common finding in ADHD research and human lesion and functional imaging studies have indicated that this measure may reflect the efficiency with which frontal systems can deploy attention over extended periods (Bellgrove, Hester, \& Garavan, 2004; Stuss et al., 2003). In the context of the current paradigm, an error of omission occurs when a participant fails to make the required Go response to a Go stimulus. Such errors may occur because the participant has misidentified a Go stimulus as a target or simply because the participant has briefly lapsed into off-task behaviour. It appears reasonable to argue therefore that the mechanisms underlying omissions are distinct from those underlying errors of commission, with the latter related to a failure to overcome the prepotency of the Go response. In contrast, there was no correlation between commission errors and either error awareness, variability or errors of omission further underlining the apparent separation between action monitoring and inhibitory control. Previous work has shown that both children and adults with ADHD are consistently more susceptible to errors on measures of sustained attention (Willcutt, Doyle, Nigg, Faraone, \& Pennington, 2005; Woods, Lovejoy, \& Ball, 2002). In line with recent explanatory models of ADHD that argue that the disorder arises from the combination of multiple pathophysiological processes (Castellanos, Sonuga-Barke, Milham, \& Tannock, 2006; Sonuga-Barke, 2003) there are grounds to suggest that ADHDrelated deficits in error awareness might arise from a deficit in top-down attentional control processes that are distinct from those involved in response inhibition.

The ERP results highlight neurophysiological abnormalities at specific stages of error processing. While the ADHD and control groups had comparable ERN amplitudes, significant differences were found at the latency of the early positivity (140-240 ms). This abnormality was evident across all response conditions, including correct Go responses. As noted previously, the correct-response negativity, which shares the same latency and scalp topography as the ERN, is thought to reflect the ongoing activity of a performance monitoring system which detects factors such as response uncertainty, conflict or changes in reward probability (Vidal et al., 2000). Similarly, the early positivity was evident on Go trials as well as error trials suggesting that it indexes aspects of continuous performance monitoring that are not specific to errors. It is thought that early, pre-conscious performance monitoring facilitates the detection of subthreshold levels of conflict or uncertainty that do not necessarily result in errors but signal the need for fine-grained performance adjustments (Coles, Scheffers, \& Holroyd, 2001).

A similar early positive component has been noted in previous ERP studies (Luu, Collins, \& Tucker, 2000; Ruchsow et al., 2006; Van Veen \& Carter, 2002) and a previous source analysis has suggested that it may share the same dorsal ACC generator as the ERN (Van Veen \& Carter, 2002). Our dipole modelling also produced an identical dorsal ACC source solution for the ERN, CRN and early positivity in both participant groups but the fact that there were group differences in the amplitude of the early positivity and not the ERN, suggests that the two are dissociable. Ruchsow et al. (2006) have also dissociated these components by reporting that while the ERN distinguishes patients with borderline personality disorder from controls, the early positivity does not. Furthermore, the scalp topographies in Fig. 4 show that the ERN and early positivity are distributed over slightly different regions. The limited spatial resolution of source analysis here precludes a confident dissociation of spatially and temporally overlapping components. Nevertheless, the present findings indicate an abnormality at a specific stage of pre-conscious performance monitoring (i.e. the early positivity) in ADHD. This deficit is not directly related to error processing but may contribute to poorer implementation of cognitive control in the ADHD group. Further work will be required to elucidate the functional significance of the early positivity.

Studies by Nieuwenhuis, Ridderinkhof, Blom, Band, and Kok (2001) and O'Connell et al. (2007) have demonstrated that the Pe is only present if participants are aware of their errors. However, clinical studies that have used the Pe as an index of error processing have not controlled for possible group differences in awareness. Our finding that participants with ADHD still had attenuated Pe components after isolating aware errors therefore provides the first direct evidence that conscious aspects of error processing are impaired in this disorder. Our findings mirror those of Wiersema et al. (2005) and Jonkman et al. (2007) who reported differences in the amplitude of the Pe, and not the ERN, in a group of children with ADHD (Overtoom et al., 2002 also report evidence of a reduced $\mathrm{Pe}$ ). In contrast however, two other studies of childhood ADHD (Burgio-Murphy et al., 2007; Liotti et al., 2005) have reported ERN abnormalities but no differences in Pe amplitude. Inconsistencies across studies may not be surprising since both the ERN and Pe are sensitive to a variety of task-specific factors such as error rate, emphasis on speed versus accuracy and stimulus saliency that could have differential effects on participants with and without ADHD (Falkenstein, Hoormann, Christ, \& Hohnsbein, 2000; Overbeek et al., 2005). The paradigm used in the present study was specifically designed to challenge conscious error processing by having competing types of response inhibition rules thereby increasing the likelihood that some errors would go unnoticed. It may be that Pe abnormalities in ADHD are more apparent when awareness is challenged in this manner. A further issue to consider is that the ERN is subject to developmental changes, increasing steadily with age, while the Pe remains unaffected (Hogan, Vargha-Khadem, Kirkham, \& Baldeweq, 2005). It is possible that ADHD-related differences in ERN amplitude arise from a developmental lag that is resolved by adulthood.

The source analysis results of the present study are striking in that they relate Pe dysfunction in the ADHD group to abnormalities within a specific brain region. While the Pe of the control group was modelled with a two source solution that included a more anterior ACC region and a posterior generator in the region of the posterior cingulate and precuneus, only a posterior generator was indicated for the ADHD group. By seeding a dipole in the ACC and applying the new model to the ERP waveform of each participant it was possible to demonstrate a reduction of activity within this region following aware errors at the latency of the Pe. Furthermore, statistical 
analysis indicated that activity in the region of the posterior source was equivalent across groups suggesting that Pe reductions in the ADHD group may be attributable to reduced activity in the ACC. It is important to note however that the results of source analysis should be interpreted with caution in light of the inverse problem and the limited spatial resolution of this approach. We also draw attention to the study by Rubia et al. (2005) which reported reduced activation around the posterior cingulate cortex/precuneus in adolescents with ADHD during inhibition and error detection on a stop-signal task. Further investigation combining ERP and brain imaging techniques would be desirable to isolate the affected brain region with greater spatial accuracy.

There were clear similarities between the Pe effects discussed above and those found for the electrodermal activity data. For unaware errors, both participant groups exhibited a marked absence of the autonomic response that is usually seen following conscious recognition of significant events (O'Keeffe, Dockree, \& Robertson, 2004; Zahn, Grafman, \& Tranel, 1999) but EDA was attenuated in the ADHD group relative to the control group across all conditions. According to models of EDA, this measure reflects heightened processing of stimuli with affective significance to healthy individuals (Zahn et al., 1999) and an fMRI study by Critchley, Tang, Glaser, Butterworth, and Dolan (2005) has demonstrated that prefrontal regions, including the ACC, are involved in modulating autonomic system activity following action errors. Significantly reduced EDA following both correct and incorrect responses to No-Go targets suggests that previous reports of decreased post-error arousal in ADHD (O'Connell, Bellgrove, Dockree, \& Robertson, 2004) are not purely attributable to awareness deficits but reflect differences in affective responsiveness to significant task events. Interestingly, these findings mirror those of a previous study conducted in our laboratory in which it was found that patients with frontal damage following traumatic brain injury had attenuated EDA to errors after controlling for awareness (O'Keeffe et al., 2004). The slow latency of SCRs (onset up to $0.5-1 \mathrm{~s}$ after a stimulus and peaking at 3 or $4 \mathrm{~s}$ ), coupled with the speed of stimulus presentation in the current study, makes it difficult to determine whether autonomic activity acts as a somatic marker that helps to triggers error awareness or if in fact it is one of the products of conscious error detection (Bechara, Damasio, Damasio, \& Lee, 1999; Critchley et al., 2003; Hajcak, McDonald, \& Simons, 2003). This is an interesting and important question for future studies.

Differences in the amplitude of the Pe and EDA point to abnormalities in conscious aspects of error-processing in ADHD. Since the ADHD group had attenuated Pe amplitudes, even when controlling for awareness, it follows that the Pe is probably not a direct, allor-nothing reflection of awareness. In addition, we found no group differences in the degree of post-error slowing after an aware error suggesting that this abnormality does not arise from reduced error correction. In light of the present data, a plausible characterisation of the Pe reduction seen in ADHD is that it is a reflection of differences in the conscious evaluation of the error event and may therefore arise from a more general motivational deficit. A number of researchers have argued that abnormal reinforcement processes and insensitivity to punishment play a central role in the development of ADHD and contribute to poorer performance on executive tasks (Castellanos et al., 2006; Sonuga-Barke, 2003). According to Castellanos et al. (2006), motivational impairments should impact upon executive function in situations that have high affective content or when task performance is dependent on one's appraisal of the affective significance of an event or stimulus. This prediction appears to be supported by the present data and previous reports of abnormalities in another ERP component which is thought to index the processing of motivational significance, the P3b (Barry, Johnstone, \& Clarke, 2003).
A major goal of clinical research, including that in ADHD, is the identification of biomarkers that would enhance the validity and specificity of diagnosis and inform treatment. Electrophysiological measures of error-processing, highlighted in the present study, may have utility in this regard and recent pharmacological studies have begun to explore the neurochemical basis of these components (Jonkman et al., 2007; Overbeek et al., 2005; Tieges, Ridderinkhof, Snel, \& Kok, 2004; Zirnheld et al., 2004). There is good evidence to suggest that the processes indexed by the ERN and Pe are mediated by different neurotransmitter systems. For example, pharmacological agents acting directly or indirectly on the dopamine system, such as amphetamine have strong effects on the amplitude of the ERN but not the Pe (de Bruijn, Hulstijn, Verkes, Ruigt, \& Sabbe, 2004). Jonkman et al. (2007) have reported a normalisation of Pe amplitudes amongst children with ADHD who were administered methylphenidate, a drug that increases the level of noradrenaline in prefrontal cortex, as well as increasing the action of dopamine.

It is noteworthy that a number of psychiatric disorders present with ostensibly similar error processing difficulties on cognitive measures yet the underlying neurophysiological substrates that give rise to these deficits might be quite distinct between disorders. For example, studies have reported larger amplitudes of the ERN, but normal Pe amplitudes amongst patients with obsessive-compulsive disorder (Ruchsow et al., 2005), smaller ERN and smaller Pe in autism spectrum disorder (Vlamings, Jonkman, Hoeksma, van Engeland, \& Kemner, 2008) and smaller ERN, but normal Pe amplitudes amongst patients with schizophrenia (Mathalon et al., 2002; Morris et al., 2006). Thus electrophysiological measures, such as those used in the present study, may have valuable clinical utility in parsing complex cognition into its component physiological processes.

In summary, while requiring replication to account for possible effects of comorbidity, medication and sample size, the present study has identified three potentially separate deficits associated with adult ADHD; poor response inhibition, reduced error awareness and abnormal responsiveness to errors that reach awareness. Awareness of motor, language, cognitive and behavioural deficits is dissociable in clinical populations and some authors have proposed that the neural circuits responsible for self-awareness in these different domains are at least partly separable (Turner \& Levine, 2004). An important challenge for future work will be to ascertain whether awareness deficits in ADHD extend beyond the detection of momentary action errors and to assess their impact on everyday-life functioning. The electrophysiological impairments exhibited by the adult ADHD group can be broadly subdivided into those reflecting differences in ongoing performance monitoring (early positivity) and those reflecting conscious subjective processing of errors (Pe, EDA). Comparisons with studies of other clinical populations and correlations with symptom severity suggest that the present findings may have a degree of specificity for ADHD. A lack of awareness of one's errors may help to explain deficits of self-awareness that are seen in a range of clinical conditions.

\section{Acknowledgments}

The work reported herein was supported by the Government of Ireland Research Scholarship in the Humanities and Social Sciences to RG O'Connell and is administered by the Irish Research Council for the Humanities and Social Sciences. This work was also supported in part by a grant from the U.S. National Institute of Mental Health (MH65350 to JJF). The authors would like to thank Dr. Sherlyn Yeap and Dr. Simon Kelly for their excellent technical support and all those who participated in this study. 


\section{References}

A.P.A. (2000). (4th ed.). Diagnostic and statistical manual of mental disorders Washington, DC: A.P.A.

Barry, R. J., Johnstone, S. J., \& Clarke, A. R. (2003). A review of electrophysiology in attention-deficit/hyperactivity disorder. II. Event-related potentials. Clinical Neurophysiology, 114(2), 184-198

Bechara, A., Damasio, H., Damasio, A. R., \& Lee, G. P. (1999). Different contributions of the human amygdala and ventromedial prefrontal cortex to decision-making. Journal of Neuroscience, 19(13), 5473-5481.

Bellgrove, M. A., Hester, R. L., \& Garavan, H. (2004). The functional neuroanatomical correlates of response variability: Evidence from a response inhibition task. Neuropsychologia, 42(14), 1910-1916.

Berg, P., \& Scherg, M. (1994). A multiple source approach to the correction of eye artifacts. Electroencephalography \&' Clinical Neurophysiology, 90, 229-241.

Brazdil, M., Roman, R., Daniel, P., \& Rektor, I. (2005). Intracerebral error-related negativity in a simple Go/NoGo task. Journal of Psychophysiology, 19(4), 244255.

Brown, J. W., \& Braver, T. S. (2005). Learned predictions of error likelihood in the anterior cingulate cortex. Science, 307(5712), 1118-1121.

Burgio-Murphy, A., Klorman, R., Shaywitz, S. E., Fletcher, J. M., Marchione, K. E., Holahan, J., et al. (2007). Error-related event-related potentials in children with attention-deficit hyperactivity disorder, oppositional defiant disorder, reading disorder, and math disorder. Biological Psychology, 75(1), 75-86.

Bush, G., Valera, E. M., \& Seidman, L. J. (2005). Functional neuroimaging of attention-deficit/hyperactivity disorder: A review and suggested future directions. Biological Psychiatry, 57(11), 1273-1284.

Castellanos, F. X., Sonuga-Barke, E. J. S., Milham, M. P., \& Tannock, R. (2006). Characterizing cognition in ADHD: Beyond executive dysfunction. Trends in Cognition Science, 10(3), 117-123.

Coles, M. G., Scheffers, M. K., \& Holroyd, C. B. (2001). Why is there an ERN/Ne on correct trials? Response representations, stimulus-related components, and the theory of error processing. Biological Psychology, 56, 173-189.

Conners, C. K., Erhardt, D., \& Sparrow, E. (2003). Conners Adult ADHD Rating Scales (CAARS). Toronto: MHS.

Critchley, H. D., Mathias, C. J., Josephs, O., O’Doherty, J., Zanini, S., Dewar, B.-K., et al. (2003). Human cingulate cortex and autonomic control: Converging neuroimaging and clinical evidence. Brain, 126, 2139-2152.

Critchley, H. D., Tang, J., Glaser, D., Butterworth, B., \& Dolan, R. J. (2005). Anterior cingulate activity during error and autonomic response. NeuroImage, 27(4), 885-895.

Dawson, M. E., Schell, A. M., \& Filion, D. L. (2000). The electrodermal system. In J. T. Cacioppo (Ed.), Handbook of psychophysiology. USA: Cambridge University Press.

Debener, S., Ullsperger, M., Siegel, M., Fiehler, K., von Cramon, D., \& Engel, A. (2006). Trial-by-trial coupling of concurrent electroencephalogram and functional magnetic resonance imaging identifies the dynamics of performance monitoring. Journal of Neuroscience, 25(50), 11730-11737.

de Bruijn, E. R., Hulstijn, W., Verkes, R. J., Ruigt, G. S., \& Sabbe, B. G. (2004). Druginduced stimulation and suppression of action monitoring in healthy volunteers. Psychopharmacology, 177(1-2), 151-160.

Falkenstein, M. (2004). ERP correlates of erroneous performance. In M. Ullsperger \& M. Falkenstein (Eds.), Errors, conflicts and the brain. Current opinions on performance monitoring (pp. 5-14). Leipzig: Max-Planck-Institut fur Kognitions-und Neurowissenschaften.

Falkenstein, M., Hoormann, J., Christ, S., \& Hohnsbein, J. (2000). ERP components on reaction errors and their functional significance: A tutorial. Biological Psychology, 51, 87-107.

Fiehler, K., Ullsperger, M., \& von Cramon, D. Y. (2004). Neural correlates of error detection and error correction: Is there a common neuroanatomical substrate? European Journal of Neuroscience, 19(11), 3081-3087.

Franken, I. H. A., van Strien, J. W., Franzek, E. J., \& van de Wetering, B. J. (2007). Errorprocessing deficits in patients with cocaine dependence. Biological Psychology, 75(1), 45-51.

Garavan, H., Ross, T. J., Murphy, K., Roche, R. A. P., \& Stein, E. A. (2002). Dissociable executive functions in the dynamic control of behaviour: Inhibition, error detection, and correction. NeuroImage, 17, 1820-1829.

Hajcak, G., McDonald, N., \& Simons, R. F. (2003). To err is autonomic: Errorrelated brain potentials, ANS activity, and post-error compensatory behavior. Psychophysiology, 40(6), 895-903.

Herrmann, M. J., Rommler, J., Ehlis, A. C., Heidrich, A., \& Fallgatter, A. J. (2004). Source localization (LORETA) of the error-related negativity (ERN/Ne) and positivity (Pe). Cognitive Brain Research, 20(20), 294-299.

Hester, R., Foxe, J. J., Molholm, S., Shpaner, M., \& Garavan, H. (2005). Neural mechanisms involved in error processing: A comparison of errors made with and without awareness. Neurolmage, 27(3), 602-608.

Hogan, A. M., Vargha-Khadem, F., Kirkham, F. J., \& Baldeweq, T. (2005). Maturation of action monitoring from adolescence to adulthood: An ERP study. Developmental Science, 8(6), 525-534.

Holroyd, C. B., Niuwenhuis, S., Mars, R. B., \& Coles, M. G. H. (2004). Anterior cingulate cortex, selection for action, and error processing. In M. I. Posner (Ed.), Cognitive neuroscience of attention. New York: Guilford.

Jonkman, L. M., van Melis, J. J. M., Kemner, C., \& Markus, C. R. (2007). Methylphenidate improves deficient error evaluation in children with ADHD: An event-related brain potential study. Biological Psychology, 76(3), 217-229.

Lijffijt, M., Kenemans, J. L., Verbaten, M. N., \& van Engeland, H.(2005). A meta-analytic review of stopping performance in attention-deficit/hyperactivity disorder:
Deficient inhibitory motor control? Journal of Abnormal Psychology, 114(2), 216-222.

Liotti, M., Pliszka, S. R., Perez, R., Kothmann, D., \& Woldorff, M. G. (2005). Abnormal brain activity related to performance monitoring and error detection in children with ADHD. Cortex, 41(3), 377-388.

Luu, P., Collins, P., \& Tucker, D. (2000). Mood, personality, and self-monitoring: Negative affect and emotionality in relation to frontal lobe mechanisms of error monitoring. Journal of Experimental Psychology - General, 129(1), 43-60.

Mathalon, D. H., Fedor, M., Faustman, W. O., Gray, M., Askari, N., \& Ford, J. M. (2002). Response-monitoring dysfunction in schizophrenia: An event-related brain potential study. Journal of Abnormal Psychology, 111, 22-41.

McAvinue, L., O'Keeffe, F. M., McMackin, D., \& Robertson, I. H. (2005). Impaired sustained attention and error awareness in traumatic brain injury: Implications for insight. Neuropsychological Rehabilitation, 15(5), 569-587.

Morris, S. E., Yee, C. M., \& Nuechterlein, K. M. (2006). Electrophysiological analysis of error monitoring in schizophrenia. Journal of Abnormal Psychology, 115(2), 239-250.

Nieuwenhuis, S., Ridderinkhof, K. R., Blom, J., Band, G. P., \& Kok, A. (2001). Errorrelated brain potentials are differentially related to awareness of response errors: Evidence from an antisaccade task. Psychophysiology, 38(5), 752-760.

Nieuwenhuis, S., Schweiser, T. S., Mars, R. B., Botvinick, M. M., \& Hajcak, G. (2007) Error-likelihood prediction in the medial frontal cortex: A critical evaluation. Cerebral Cortex, 17(7), 1570-1581.

Norman, D. A., \& Shallice, T. (1986). Attention to action: Willed and automatic contro of behaviour. In R. J. Davidson, G. E. Schwarz, \& D. Shapiro (Eds.), Consciousness and self-regulation (pp. 1-18). New York: Plenum Press.

O'Connell, R. G., Bellgrove, M. A., Dockree, P., \& Robertson, I. H. (2004). Reduced electrodermal response to errors predicts poor sustained attention performance in Attention Deficit Hyperactivity Disorder. NeuroReport, 15(16), 25352538.

O'Connell, R. G., Dockree, P., Bellgrove, M. A., Kelly, S. P., Hester, R., Garavan, H., et al. (2007). The role of Cingulate Cortex in the detection of errors with and without awareness: A high-density electrical mapping study. European Journal of Neuroscience, 25(8), 2571-2579.

O'Keeffe, F. M., Dockree, P. M., Moloney, P., Carton, S., \& Robertson, I. H. (2007) Characterising error-awareness of attentional lapses and inhibitory control failures in patients with traumatic brain injury. Experimental Brain Research, 180(1), 59-67.

O'Keeffe, F. M., Dockree, P. M., \& Robertson, I.H.(2004). Poor insight in traumatic brain injury mediated by impaired error processing? Evidence from electrodermal activity. Cognitive Brain Research, 22(1), 101-112.

O’Keeffe, F. M., Murray, B., Coen, R. F., Dockree, P. M., Bellgrove, M. A., Garavan, H., et al. (2007). Loss of insight in frontotemporal dementia, corticobasal degeneration and progressive supranuclear palsy. Brain, 130(3), 753-764.

Overbeek, T. J. M., Nieuwenhuis, S., \& Ridderinkhof, K. R. (2005). Dissociable components of error processing: On the functional significance of the Pe Vis-à-vis the ERN/Ne. Journal of Psychophysiology, 19(4), 319-329.

Overtoom, C. C. E., Kenemans, J. L., Verbaten, M. N., Kemner, C., van der Molen, M. W., van Engeland, H., et al. (2002). Inhibition in children with attentiondeficit/hyperactivity disorder: A psychophysiological study of the stop task. Biological Psychiatry, 51(8), 668-676.

Prigatano, G. P., \& Schachter, D. L. (1991). Awareness of deficit after brain injury: Clinical and theoretical issues. New York: Oxford University Press.

Ridderinkhof, K. R., Ullsperger, M., Crone, E. A., \& Nieuwenhuis, S. (2004). The role of the medial frontal cortex in cognitive control. Science, 306, 443-447.

Rubia, K., Smith, A. B., Brammer, M. J., Toone, B., \& Taylor, E. (2005). Abnormal brain activation during inhibition and error detection in medication-naive adolescents with ADHD. American Journal of Psychiatry, 162(2), 1067-1075.

Ruchsow, M., Gron, G., Reuter, K., Spitzer, M., Hermle, L., \& Kiefer, M. (2005). Errorrelated brain activity in patients with obsessive-compulsive disorder and in healthy controls. Journal of Psychophysiology, 19(4), 298-304.

Ruchsow, M., Walter, H., Buchheim, A., Martius, P., Spitzer, M., Kachele, H., et al. (2006). Electrophysiological correlates of error processing in borderline personality disorder. Biological Psychology, 72(2), 133-140.

Schachar, R. J., Chen, S., Logan, G. D., Ornstein, T. J., Crosbie, J., Ickowicz, A., et al. (2004). Evidence for an error monitoring deficit in Attention Deficit Hyperactivity Disorder. Journal of Abnormal Child Psychology, 32(3), 285-293.

Seidman, L. J. (2006). Neuropsychological functioning in people with ADHD across the lifespan. Clinical Psychology Review, 4, 466-485.

Seidman, L. J., Valera, E. M., \& Makris, N. (2005). Structural brain imaging of attentiondeficit/hyperactivity disorder. Biological Psychiatry, 57(11), 1263-1272.

Shalgi, S., O'Connell, R. G., Deouell, L. Y., \& Robertson, I. H. (2007). Absent minded but accurate: Delaying responses increases accuracy but decreases error awareness. Experimental Brain Research, 182(1), 119-124.

Sonuga-Barke, E. J. S. (2003). The dual pathway model of AD/HD: An elaboration of neuro-developmental characteristics. Neuroscience \& Biobehavioral Reviews, 27(7), 593-604

Sowell, E. R., Thompson, P. M., Welcome, S. E., Henkenius, A. L., Toga, A. W., \& Peterson, B. S. (2003). Cortical abnormalities in children and adolescents with attentiondeficit hyperactivity disorder. The Lancet, 362, 1699-1707.

Spitzer, R. L., Williams, J. B., Gibbon, M., \& First, M. B. (1992). The structured clinical interview for DSM-III-R (SCID), I: history, rationale, and description. Archives of General Psychiatry, 49, 624-629.

Stuss, D. T., Murphy, K. J., Binns, M. A., \& Alexander, M. P. (2003). Staying on the job: The frontal lobes control individual performance variability. Brain, 126 2363-2380. 
Tieges, Z., Ridderinkhof, K. R., Snel, J. W., \& Kok, A. (2004). Caffeine strengthens action monitoring: Evidence from the error-related negativity. Cognitive Brain Research, 21, 87-93.

Turner, G. R., \& Levine, B. (2004). Disorders of executive functioning and selfawareness. In J. Ponsford (Ed.), Cognitive and behavioural rehabilitation. New York: Guilford.

van Meel, C. S., Heslenfeld, D. J., Oosterlaan, J., \& Sergeant, J. A. (2007). Adaptive control deficits in attention-deficit/hyperactivity disorder (ADHD): The role of error processing. Psychiatry Research, 151(3), 211-220.

Van Veen, V., \& Carter, C. S. (2002). The timing of action-monitoring processes in the anterior cingulate cortex. Journal of Cognitive Neuroscience, 14(4), 593602.

Vidal, F., Hasbrouc, T., Grapperonc, J., \& Bonnet, M. (2000). Is the 'error negativity' specific to errors? Biological Psychology, 51(2-3), 109-128.

Vlamings, P. H., Jonkman, L. M., Hoeksma, M. R., van Engeland, H., \& Kemner, C. (2008). Reduced error monitoring in children with autism spectrum disorder: An ERP study. European Journal of Neuroscience, 28(2), 399-406.
Ward, M. F., Wender, P. H., \& Reimherr, F. W. (1993). The WURS: A rating scale to aid in the retrospective diagnosis of ADHD in childhood. American Journal of Psychiatry, $150,885-890$.

Wiersema, J. R., Van der Meere, J., \& Roeyers, H. (2005). ERP correlates of impaired error monitoring in children with ADHD. Journal of Neural Transmission, 112(10), 1417-1430.

Willcutt, E. G., Doyle, A. E., Nigg. J. T., Faraone, S. V., \& Pennington, B. F. (2005). Validity of the executive function theory of ADHD: A meta-analytic review. Biological Psychiatry, 57(11), 1336-1346.

Woods, S. P., Lovejoy, D. W., \& Ball, J. D. (2002). Neuropsychological characteristics of adults with ADHD: A comprehensive review of initial studies. The Clinical Neuropsychologist, 16(1), 12-34.

Zahn, T. P., Grafman, J., \& Tranel, D. (1999). Frontal lobe lesions and electroderma activity: Effects of significance. Neuropsychologia, 37, 1227-1241.

Zirnheld, P. J., Carroll, C. A., Kieffaber, P. D., O'Donnell, B. F., Shekhar, A., \& Hetrick W. (2004). Haloperidol impairs learning and error-related negativity in humans. Journal of Cognitive Neuroscience, 16(6), 1098-1112. 